10 J. E. Rowe u. R. A. Forman, J. Appl. Phys. 39, 1917 [1968].

11 W. D. Gill, P. F. Lindquist u. R. H. Bube, Proc. 7-th Photovoltaic Spec. Conf. 47 [1968].

12 E. P. Warekois, M. C. Lavine, A. N. Mariano u. H. C. Gatos, J. Appl. Phys. 33, 1917 [1962].

13 R. S. Bebrick u. W. W. Scanlon, J. Chem. Phys. 27, 607 [1957].

14 W. J. Wösten, J. Appl. Phys. 33, 246 [1962].
15 M. B. Prince, J. Appl. Phys. 26, 1 [1955].

16 A. E. Potter u. R. L. Schalla, Proc. 6-th Photovoltaic Conf. I, 24 [1967].

17 C. A. Mead, in: B. Schwartz (editor), Ohmic Contacts to Semiconductors, The Electrochemical Society, New York 1969, S. 3.

18 R. W. Aldrich u. D. A. Cusano, Technical Report AFAPLTR-65-8, 1965.

\title{
Minimal Basis Set ab initio LCGO Calculations
}

\author{
Patricia A. Clark * and H. Preuss \\ Institut für Theoretische Chemie, D-7000 Stuttgart, Relenbergstraße 32 \\ (Z. Naturforsch. 27 a, 1294-1299 [1972] ; received 19 May 1972)
}

\begin{abstract}
$a b$ initio calculations using a minimal basis set of Gauss functions have been carried out on the molecules $\mathrm{CH}_{4}, \mathrm{C}_{2} \mathrm{H}_{2}, \mathrm{C}_{2} \mathrm{H}_{4}, \mathrm{~N}_{2}, \mathrm{HCN}$ and $\mathrm{CH}_{3} \mathrm{NH}_{2}$ in order to test the usefulness of the basis set in predicting properties such as charge distributions and dipole moments in large molecules.
\end{abstract}

\section{Introduction}

As interest in $a b$ initio calculations grows to include the investigation of the electronic structures of increasingly larger molecules, it becomes necessary to find more efficient Gaussian-type orbital (GTO) basis sets in order for the calculation to be practicable in terms of the amount of computer time necessary. Preuß has introduced and extensively studied the use of pure Gaussian functions as basis sets ${ }^{1-4}$ and has developed a basis set of 5 GTO's for the description of the core configuration $(1 \mathrm{~s})^{2}(2 \mathrm{~s})^{2}$ for the second-row elements ${ }^{4}$. HARTMANN ${ }^{5}$ has subsequently used these in an investigation of the geometry of the methylammonium ion.

POPLE and coworkers ${ }^{6-10}$ have reported extensive studies on Gaussian expansions of Slater-type orbitals (STO) and on energy-minimized, minmal GTO basis sets. Another approach which has been used in order to obtain greatest accuracy with a minimum number of functions is to add Gaussian lobes in the bond regions $3,5,11,12$.

In the present investigation on some simple molecules, each hydrogen atom is represented by one Gaussian function ${ }^{13}$ and each carbon and nitrogen atom by three Gaussian functions ${ }^{14}$ for the configuration $(1 \mathrm{~s})^{2}(2 \mathrm{~s})^{2}$ and two Gaussian functions for each of the $2 \mathrm{p}_{x}, 2 \mathrm{p}_{y}$, and $2 \mathrm{p}_{z}$ atomic orbitals. The p-type functions have been optimized for the carbon atom and for the nitrogen cation and anion, respec-

Reprint requests to Prof. Dr. H. Preuss, Institut für Theoretische Chemie, D-7000 Stuttgart, Relenbergstraße 32. tively. Values for the exponents $\eta$ in the Gaussian functions

$$
\varphi_{\lambda}\left(\boldsymbol{r}_{\lambda}, \eta_{\lambda}\right)=\left(\frac{2 \eta_{\lambda}}{\pi}\right)^{3 / 4} \exp \left\{-\eta_{\lambda}\left(\boldsymbol{r}-\boldsymbol{r}_{\lambda}\right)^{2}\right\}
$$

are given in Table 1. All calculations reported here have been carried out using the closed-shell MOLPRO system ${ }^{15}$.

Table 1. Exponents $\eta$ for energy-optimized Gaussian functions for $\mathrm{H}, \mathrm{C}$, and $\mathrm{N}$.

\begin{tabular}{lclll}
\hline & s-type & & p-type & $E_{\text {total }}$ \\
\hline $\mathrm{H}$ & $0.283^{13}$ & & & \\
$\mathrm{C}^{2+}$ & 47.914 & $\mathrm{C}$ & 0.2920 & -36.14991 \\
& 6.90 & & & \\
& 0.39 & & & \\
$\mathrm{~N}^{3+}$ & 68.5 & $\mathrm{~N}^{+}$ & 0.6275 & -51.69437 \\
& 9.90 & $\mathrm{~N}^{-}$ & 0.3085 & -51.55100 \\
& 0.59 & & & \\
\hline
\end{tabular}

\section{Results and Discussion}

The basis functions described above have been used to calculate the total energies, dipole moments, and charge distributions for $\mathrm{CH}_{4}, \mathrm{C}_{2} \mathrm{H}_{2}, \mathrm{C}_{2} \mathrm{H}_{4}, \mathrm{~N}_{2}$, $\mathrm{NH}_{3}, \mathrm{HCN}$ and $\mathrm{CH}_{3} \mathrm{NH}_{2}$. In addition, the exponents of the p-type GTO's have been varied in each molecule in order to determine which values give minimum energies for the various types of bonding. It has been found that the p-type functions optimized to give a minimum energy for the atoms do

\footnotetext{
* Permanent address: Department of Chemistry, Vassar College, Poughkeepsie, New York.
} 
Table 2. $\mathrm{CH}_{4}$ : gross atomic charges, charge densities and bond orders, and total energies.

\begin{tabular}{llllllll}
\hline $\mathrm{C} \eta_{2 \mathrm{p}}$ & $n_{\mathrm{C}}$ & $n_{\mathrm{H}}$ & $\varrho_{\mathrm{C}}$ & $\varrho_{\mathrm{H}}$ & $\varrho_{\mathrm{CH}}$ & $\varrho_{\mathrm{H} i \mathrm{H} j}$ & $E_{\text {TOT }}(\mathrm{a} . \mathrm{u})$. \\
\hline 0.2920 & 6.706 & 0.823 & 4.8418 & 0.4480 & 0.4165 & -0.0137 & -38.24294 \\
0.49 & 5.635 & 1.091 & 3.9098 & 0.8135 & 0.3782 & -0.0334 & -38.5113 \\
0.52 & 5.517 & 1.121 & 3.9764 & 0.8606 & 1.0932 & -0.1776 & -38.52655 \\
0.55 & 5.409 & 1.148 & 3.9062 & 0.9048 & 1.0954 & -0.1911 & -38.53801 \\
0.60 & 5.249 & 1.188 & 3.6529 & 0.9724 & 0.3455 & -0.0434 & -38.55018 \\
0.65 & 5.110 & 1.223 & 3.5692 & 1.0333 & 0.3314 & -0.0474 & -38.55535 \\
0.70 & 4.887 & 1.253 & 3.4994 & 1.0885 & 0.3181 & -0.0511 & -38.55501 \\
0.75 & 4.878 & 1.281 & 3.4402 & 1.1386 & 0.3056 & -0.0545 & -38.55027 \\
0.80 & 4.780 & 1.305 & 3.5455 & 1.1843 & 1.0801 & -0.2823 & -38.54202 \\
0.85 & 4.692 & 1.327 & 3.5007 & 1.2263 & 1.0729 & -0.2971 & -38.53094 \\
\hline
\end{tabular}

Table 3. $\mathrm{NH}_{3}$ : gross atomic charges, charge densities and bond orders, dipole moments, and total energies.

\begin{tabular}{|c|c|c|c|c|c|c|c|c|}
\hline $\mathrm{N} \eta_{2 p}$ & $n_{\mathrm{N}}$ & $n_{\mathrm{H}}$ & $\varrho N$ & $\varrho_{\mathrm{H}}$ & $\varrho \mathrm{NH}$ & $\varrho_{\mathrm{H} i \mathrm{H} j}$ & $\begin{array}{l}\text { Dipole } \\
\text { Moment(D) }\end{array}$ & $E_{\text {тот }}$ (a.u.) \\
\hline 0.4680 & 7.2158 & 0.928 & 5.9923 & 0.6335 & 0.3633 & -0.0345 & 1.2032 & -53.54658 \\
\hline 0.3085 & 7.7640 & 0.7453 & 6.5005 & 0.3897 & 0.3794 & -0.0120 & 1.2073 & -53.18537 \\
\hline 0.6275 & 6.7113 & 1.0965 & 5.6747 & 0.8991 & 0.3027 & -0.0528 & 0.7387 & -53.64808 \\
\hline 0.30 & 7.7789 & 0.7404 & 6.5171 & 0.3835 & 0.3791 & -0.0111 & 1.1503 & -53.15296 \\
\hline 0.35 & 7.6486 & 0.7838 & 6.3785 & 0.4372 & 0.3802 & -0.0170 & 1.3472 & -53.31988 \\
\hline 0.40 & 7.4678 & 0.8440 & 6.2046 & 0.5155 & 0.3770 & -0.0243 & 1.3400 & -53.43905 \\
\hline 0.45 & 7.2811 & 0.9063 & 6.0441 & 0.6021 & 0.3678 & -0.0318 & 1.2470 & -53.52311 \\
\hline 0.50 & 7.1050 & 0.9655 & 5.9089 & 0.6895 & 0.3537 & -0.0388 & 1.1179 & -53.58095 \\
\hline 0.55 & 6.9392 & 1.0203 & 5.7995 & 0.7746 & 0.3358 & -0.0450 & 0.9736 & -53.61880 \\
\hline 0.60 & 6.7886 & 1.0705 & 5.7133 & 0.8563 & 0.3151 & -0.0504 & 0.8230 & -53.64115 \\
\hline 0.65 & 6.6507 & 1.1164 & 5.6474 & 0.9333 & 0.2921 & -0.0545 & 0.6692 & -53.65133 \\
\hline 0.70 & 6.5241 & 1.1586 & 5.5993 & 1.0065 & 0.2672 & -0.0575 & 0.5128 & -53.65189 \\
\hline 0.75 & 6.4072 & 1.1976 & 5.5665 & 1.0758 & 0.2408 & -0.0593 & 0.3530 & -53.64483 \\
\hline 0.80 & 6.2986 & 1.2338 & 5.5473 & 1.1416 & 0.2128 & -0.0603 & 0.1884 & -53.63176 \\
\hline 0.85 & 6.1972 & 1.2676 & 5.5399 & 1.2044 & 0.1835 & -0.2287 & 0.0186 & -53.61397 \\
\hline
\end{tabular}

not yield a minimum energy for the molecules; similar results have been reported by HEHRE et al. ${ }^{\boldsymbol{6}}$. On the other hand, the dipole moments and charge distributions are generally more adequately described with the best-atom functions.

Typical results for these molecules may be illustrated by those for $\mathrm{CH}_{4}$ and $\mathrm{NH}_{3}$, which are summarized in Tables 2 and 3 , respectively. Here are given, as a function of the Gaussian exponent $\eta_{2 p}$, the total energies; charge densities and bond orders $\varrho(\lambda, \mu)$,

$$
\varrho(\lambda, \mu)=\sum_{r_{\lambda}} \sum_{s_{\mu}} P_{r_{\lambda} s_{\mu}} S_{r_{\lambda} s_{\mu}}
$$

where $\mu, \lambda$ are atoms, $r, s$ are GTO's, and $P$ is given by

$$
P_{r_{\lambda} s_{\mu}}=\sum_{i}^{\text {occ.mo } 2} c_{r_{\lambda}} c_{s_{\mu}}
$$

where the $c$ 's are the coefficients of the GTO's in the occupied molecular orbitals; the gross atomic charges $n_{\lambda}$,

$$
n_{\lambda}=\sum_{\lambda} \varrho(\lambda, \lambda)+\frac{1}{2} \sum_{\mu \neq \lambda} \varrho(\mu, \lambda)
$$

and, in the case of $\mathrm{NH}_{3}$, the dipole moments. The best-atom $\eta$ 's are included; in the case of $\mathrm{N}$, where this value could not be calculated for the neutral atom, the values for $\mathrm{N}^{+}, \mathrm{N}^{-}$, and the average value of these two have been used. Figures 1 and 2 show the variation in gross atomic charges $n_{\lambda}$ for $\mathrm{C}$ in $\mathrm{CH}_{4}$ and for $\mathrm{N}$ in $\mathrm{NH}_{3}$, respectively, with $\eta$. Figure 3 shows the variation in the dipole moment of $\mathrm{NH}_{3}$ with $\eta$.

PAlKe and Lipscomb ${ }^{16}$, using STO ab initio calculations, have reported the electron density at the carbon in $\mathrm{CH}_{4}$ to be $6.534 \mathrm{e}^{-}$; here we have obtained a value of $6.706 \mathrm{e}^{-}$, which is appreciably higher. $\mathrm{NH}_{3}$ presents a better example since this molecule has a dipole moment, and a comparison of calculated and experimental values affords a better test of the method being investigated here. PALKE and LIPSCOMB ${ }^{16}$ obtain a value of $1.72 \mathrm{D}$ while the experimental value is $1.47 \mathrm{D}$; we obtain here a value of $1.20 \mathrm{D}$ using the average value, which is about as much too low as Palke and Lipscomb's 


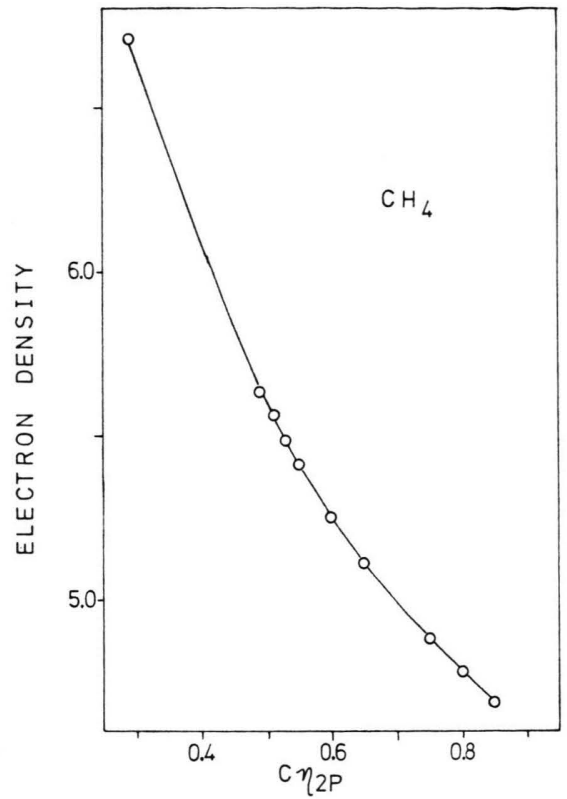

Fig. 1. Variation of electron density $\eta$ of carbon in $\mathrm{CH}_{4}$ as a function of the Gaussian exponent $\eta_{2 p}$.

value is too high. The electron density on $\mathrm{N}$ in $\mathrm{NH}_{3}$ is calculated by Palke and Lipscomb to be $7.467 \mathrm{e}^{-}$, while we obtain $7.216 \mathrm{e}^{-}$.

Table 4 summarizes the results for $\mathrm{CH}_{4}, \mathrm{NH}_{3}$, $\mathrm{C}_{2} \mathrm{H}_{2}, \mathrm{C}_{2} \mathrm{H}_{4}$ and $\mathrm{N}_{2}$. Included for comparison are the results of PALKE and LIPSCOMB ${ }^{16}$ and those of Hehre et al., who use basis sets of intermediate size.

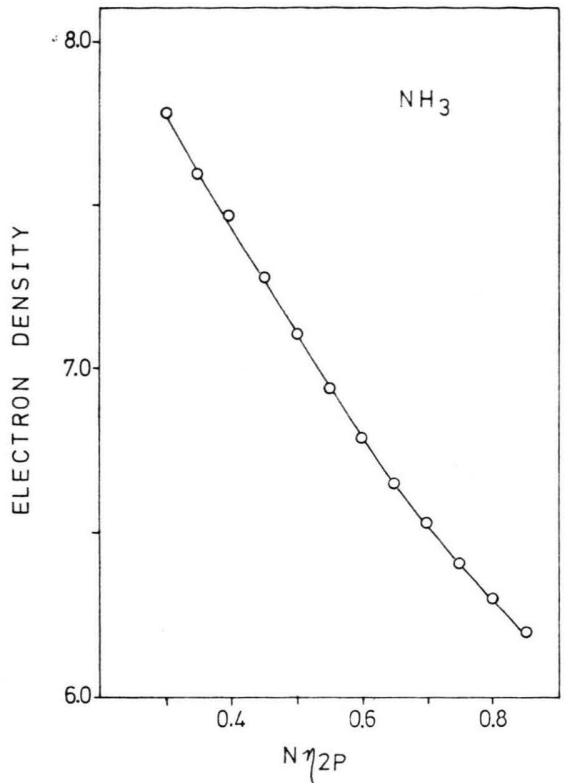

Fig. 2. Variation of the electron density $\eta$ of nitrogen in $\mathrm{NH}_{3}$ as a function of the Gaussian exponent $\eta_{2 p}$.

In some cases the results obtained here show better agreement with the more exact calculations than do those of Hehre et al. and in other cases the agreement is poorer. In all cases our results give best agreement with the more exact calculations when the atom-optimized functions are used!

For the molecules $\mathrm{HCN}$ and $\mathrm{CH}_{3} \mathrm{NH}_{2}$, the presence of both carbon and nitrogen atoms and the

Table 4. Summary of results for $\mathrm{C}_{n} \mathrm{H}_{m}$ and $\mathrm{N}_{n} \mathrm{H}_{m}$ compounds.

\begin{tabular}{|c|c|c|c|c|c|c|}
\hline Molecule & & $\eta_{2 p}$ & $E_{\text {TOT }}$ & $n_{\lambda}$ & $n_{\mathrm{H}}$ & $\begin{array}{l}\text { Dipole } \\
\text { Moment (D) }\end{array}$ \\
\hline $\mathrm{CH}_{4}$ & $\begin{array}{l}\text { best-atom } \\
\text { best-molecule } \\
\text { STO-3G }{ }^{6} \\
\text { STO } 16\end{array}$ & $\begin{array}{l}0.292 \\
0.675\end{array}$ & $\begin{array}{l}-38.2429 \\
-38.5554 \\
-\quad 39.7153 \\
-40.1141\end{array}$ & $\begin{array}{l}6.706 \\
5.060 \\
6.524 \\
6.534\end{array}$ & $\begin{array}{l}0.823 \\
1.260 \\
0.869 \\
0.867\end{array}$ & \\
\hline $\mathrm{C}_{2} \mathrm{H}_{4}$ & $\begin{array}{l}\text { best-atom } \\
\text { best-molecule } \\
\text { STO-3G }{ }^{6} \\
\text { STO } 16\end{array}$ & $\begin{array}{l}0.292 \\
0.512\end{array}$ & $\begin{array}{l}-74.4907 \\
-74.8827 \\
-77.0506 \\
-77.8343\end{array}$ & $\begin{array}{l}6.397 \\
5.700 \\
6.276 \\
6.278\end{array}$ & $\begin{array}{l}0.802 \\
1.075 \\
0.862 \\
0.860\end{array}$ & \\
\hline $\mathrm{C}_{2} \mathrm{H}_{2}$ & $\begin{array}{l}\text { best-atom } \\
\text { best-molecule } \\
\text { STO-3G } \\
\text { STO } 16\end{array}$ & $\begin{array}{l}0.292 \\
0.460\end{array}$ & $\begin{array}{l}-73.4634 \\
-73.7397 \\
-75.8415 \\
-76.6185\end{array}$ & $\begin{array}{l}6.357 \\
6.001 \\
6.187 \\
6.188\end{array}$ & $\begin{array}{l}0.643 \\
0.999 \\
0.813 \\
0.812\end{array}$ & \\
\hline $\mathrm{N}_{2}$ & $\begin{array}{l}\text { best-atom } \\
\text { best-molecule }\end{array}$ & $\begin{array}{l}0.468 \\
0.60\end{array}$ & $\begin{array}{l}-104.1320 \\
-104.2740\end{array}$ & $\begin{array}{l}7.000 \\
7.000\end{array}$ & & \\
\hline $\mathrm{NH}_{3}$ & $\begin{array}{l}\text { best-atom } \\
\text { best-molecule } \\
\text { STO-3G }{ }^{6} \\
\text { STO } 16\end{array}$ & $\begin{array}{l}0.468 \\
0.3085 \\
0.675\end{array}$ & $\begin{array}{r}-53.5466 \\
-53.1854 \\
-53.6530 \\
-55.4536 \\
-56.0050\end{array}$ & $\begin{array}{l}7.216 \\
7.7640 \\
6.590 \\
7.450 \\
7.467\end{array}$ & $\begin{array}{l}0.928 \\
0.745 \\
1.138 \\
0.850 \\
0.845\end{array}$ & $\begin{array}{l}1.203 \\
1.207 \\
0.585 \\
1.66 \\
1.72\end{array}$ \\
\hline
\end{tabular}




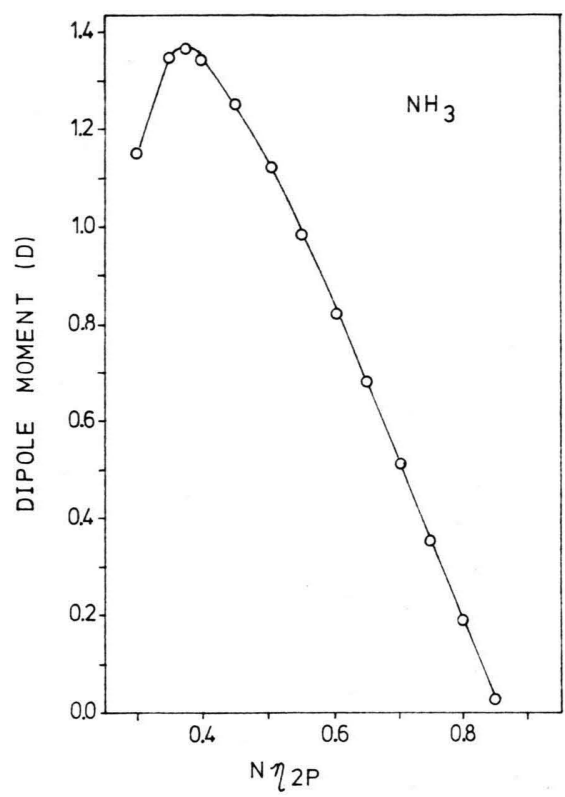

Fig. 3. Variation of the dipole moment of $\mathrm{NH}_{3}$ as a function of the Gaussian exponent $\eta_{2 p}$.

availability of experimental dipole moments afford a still better test of the method. Figures 4 and 5 show the variation in total energy as a function of the carbon and nitrogen $\eta_{2 p}$ values for $\mathrm{HCN}$ and $\mathrm{CH}_{3} \mathrm{NH}_{2}$, respectively. Figures 6 and 7 show the

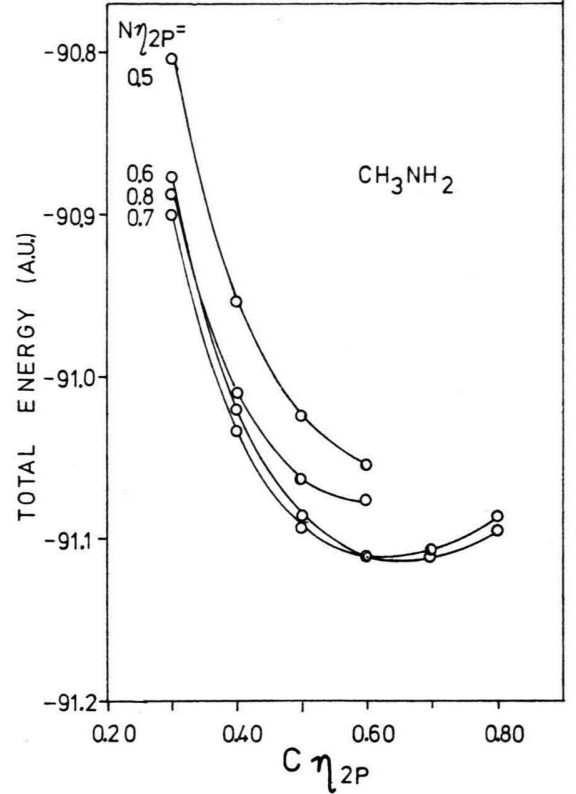

Fig. 5. Variation of the total energy (in a. u.) of $\mathrm{CH}_{3} \mathrm{NH}_{2}$ as a function of the two Gaussian exponents $\eta_{2 p}$ for $\mathrm{C}$ and $\mathrm{N}$.

variation in the dipole moments as a function of the exponents.

In both of these molecules, as in the case of those previously discussed, the lowest energies occur for $\eta_{2 p}$ much larger than in the atoms. But here the me-

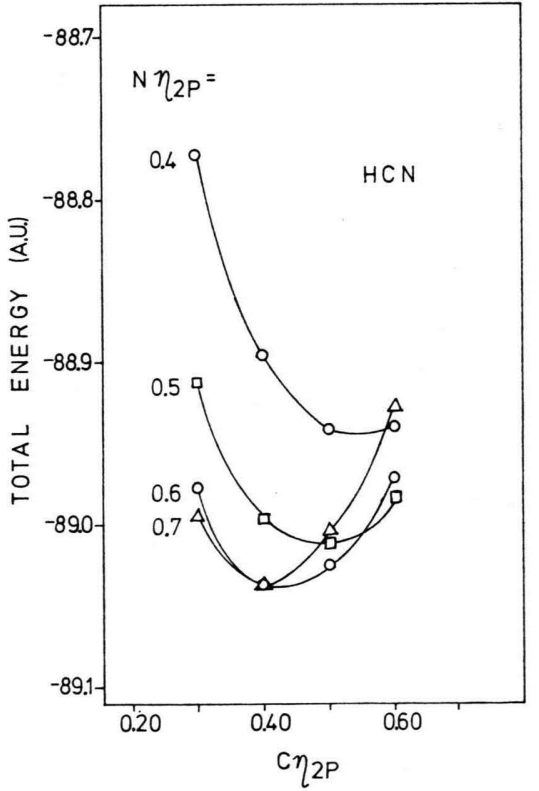

Fig. 4. Variation of the total energy (in a. u.) of $\mathrm{HCN}$ as a function of the two Gaussian exponents $\eta_{2 p}$ for $\mathrm{C}$ and $\mathrm{N}$.

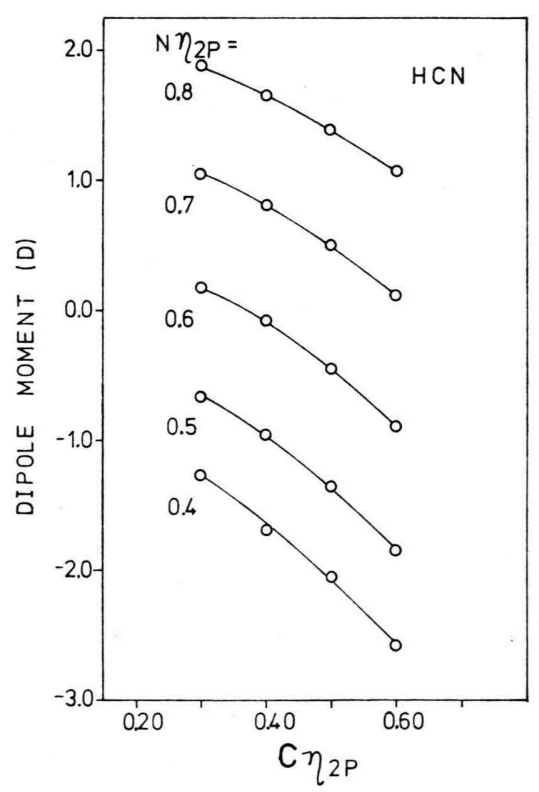

Fig. 6. Variation in the dipole moment of $\mathrm{HCN}$ as a function of the two Gaussian exponents $\eta_{2 p}$ for $\mathrm{C}$ and $\mathrm{N}$. 


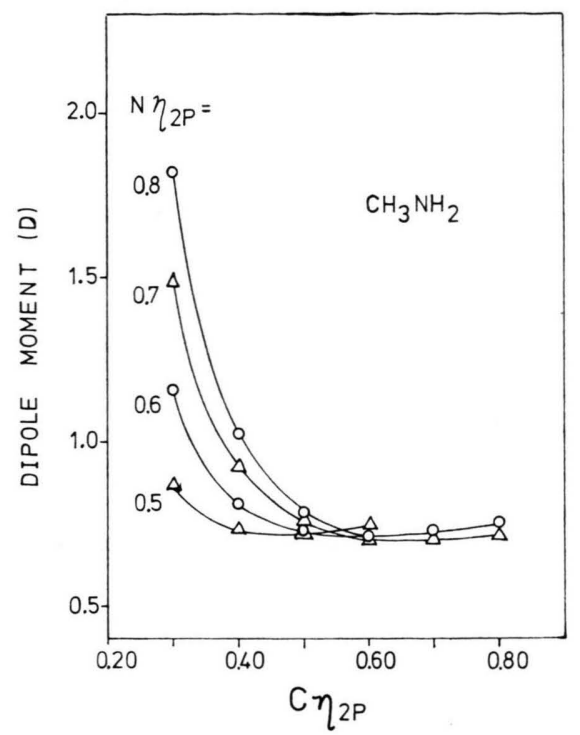

Fig. 7. Variation of the dipole mmoent of $\mathrm{CH}_{3} \mathrm{NH}_{2}$ as a function of the two Gaussian exponents $\eta_{2 p}$ of $\mathrm{C}$ and $\mathrm{N}$.

thod fails to give a reasonable dipole moment with the best atom exponents, the value for $\mathrm{HCN}$ being actually negative, about -1 . D as compared to $2.95 \mathrm{D}$ experimentally ${ }^{17}$; that for $\mathrm{CH}_{3} \mathrm{NH}_{2}$ is also too small, bring $0.7-0.8 \mathrm{D}$ as compared to $1.29 \mathrm{D}$ experimentally ${ }^{17}$. Gross atomic charges for HCN and $\mathrm{CH}_{3} \mathrm{NH}_{2}$ are given in Table 5 , with the values from other $a b$ initio calculations using larger basis sets included for comparison.

One disturbing feature of the results for HCN and $\mathrm{CH}_{3} \mathrm{NH}_{2}$ is that the predicted gross atomic charges become worse as the dipole moment improves. For example, if we choose $\mathrm{C} \eta_{2 p}=0.30$, very near the best-atom value of 0.292 , the dipole moment in HCN improves as $\mathrm{N} \eta_{2 p}$ increases, but the $\mathrm{N}$ atoms is in all cases positively charged and becomes increasingly so as $\mathrm{N} \eta_{2 \mathrm{p}}$ increases, as shown in Table 6. The results for $\mathrm{CH}_{3} \mathrm{NH}_{2}$, also included in the Table, are similar.

The difficulty in determining a good exponent for the 2p GTO's in $\mathrm{C}$ and $\mathrm{N}$ is probably due to the failure of the s-type functions used to give an adequate description of the atomic cores. When these functions are used in calculations on molecules, the p-type GTO's require a larger exponent and hence become less diffuse in space in order to better describe the $\mathrm{C}$ or $\mathrm{N}$ atom in the molecule, with the result that bonding between $\mathrm{C}$ or $\mathrm{N}$ and other atoms such as $\mathrm{H}$ is not well characterized. Evidence for this can be seen in the results of the Mulilken po-

Table 5. HCN and $\mathrm{CH}_{3} \mathrm{NH}_{2}$ : gross atomic populations and dipole moments.

\begin{tabular}{|c|c|c|c|c|c|c|c|c|}
\hline $\mathrm{HCN}:$ & $\mathrm{N} \eta_{3 \mathrm{p}}$ & $\mathrm{C} \eta_{2 p}$ & $n_{\mathrm{N}}$ & $n_{\mathrm{C}}$ & $n_{\mathrm{H}}$ & Dipole & & Moment (D) \\
\hline $\begin{array}{l}\text { This Work: } \\
\text { McLeAN } 18 \\
\text { Expt } 17\end{array}$ & $\begin{array}{l}0.3085 \\
0.4680\end{array}$ & $\begin{array}{l}0.2920 \\
0.2920\end{array}$ & $\begin{array}{l}6.8827 \\
6.7463 \\
7.082\end{array}$ & $\begin{array}{l}6.2716 \\
6.3866 \\
6.156\end{array}$ & $\begin{array}{l}0.8457 \\
0.8671 \\
0.761\end{array}$ & $\begin{array}{c}-1.1374 \\
-0.8864 \\
2.95\end{array}$ & & \\
\hline $\mathrm{CH}_{3} \mathrm{NH}_{2}{ }^{19}$ : & $\mathrm{N} \eta_{2 \mathrm{p}}$ & $\mathrm{C} \eta_{2 \mathrm{p}}$ & $n_{\mathrm{N}}$ & $n_{\mathrm{C}}$ & $n_{\mathrm{H} 1, \mathrm{H} 2}$ & $n_{\mathrm{H} 3, \mathrm{H} 4}$ & $n_{\mathrm{H} 5}$ & $\begin{array}{l}\text { Dipole } \\
\text { Moment (D) }\end{array}$ \\
\hline This Work: & $\begin{array}{l}0.3085 \\
0.4680\end{array}$ & $\begin{array}{l}0.2920 \\
0.2920\end{array}$ & $\begin{array}{l}7.9850 \\
7.3646\end{array}$ & $\begin{array}{l}6.3704 \\
6.3797\end{array}$ & $\begin{array}{l}0.5864 \\
0.7962\end{array}$ & $\begin{array}{l}0.8091 \\
0.8656\end{array}$ & $\begin{array}{l}0.8536 \\
0.9320\end{array}$ & $\begin{array}{l}0.6949 \\
0.8253\end{array}$ \\
\hline $\begin{array}{l}\text { PEDERSEN and } \\
\text { MoROKUMA } 20 \\
\text { Expt } 17\end{array}$ & & & 7.6406 & 6.3948 & 0.7424 & 0.8118 & 0.8561 & 1.29 \\
\hline
\end{tabular}

Table 6. Variation in gross atomic charges $\mathrm{n}$ in $\mathrm{HCN}$ and $\mathrm{CH}_{3} \mathrm{NH}_{2}$ as a function of $\mathrm{N} \eta_{2 p}$ with $\mathrm{C} \eta_{2 p}$ held constant at 0.30 .

\begin{tabular}{|c|c|c|c|c|c|c|c|c|c|c|}
\hline \multirow[b]{2}{*}{$\mathrm{N} \eta_{2 \mathrm{p}}$} & \multicolumn{3}{|l|}{$\mathrm{HCN}$} & \multicolumn{6}{|c|}{$\mathrm{CH}_{3} \mathrm{NH}_{2}{ }^{19}$} & \multirow[b]{2}{*}{$\begin{array}{l}\text { Dipole } \\
\text { Moment (D) }\end{array}$} \\
\hline & $n_{\mathrm{N}}$ & $n_{\mathrm{C}}$ & $n_{\mathrm{H}}$ & $\begin{array}{l}\text { Dipole } \\
\text { Moment (D) }\end{array}$ & $n_{\mathrm{N}}$ & $n_{\mathrm{C}}$ & $n_{\mathrm{H} 1}, \mathrm{H} 2$ & $n_{\mathrm{H} 3}, \mathrm{H} 4$ & $n_{\mathrm{H} 5}$ & \\
\hline 0.40 & 6.8417 & 6.2996 & 0.8587 & -1.269 & & & & & & \\
\hline 0.50 & 6.6978 & 6.4358 & 0.8663 & -0.666 & 7.2385 & 6.3775 & 0.8381 & 0.8798 & 0.9481 & 0.872 \\
\hline 0.60 & 6.5174 & 6.6348 & 0.8679 & 0.184 & 6.8872 & 6.4674 & 0.9445 & 0.8903 & 0.9756 & 1.159 \\
\hline 0.70 & 6.3354 & 6.7988 & 0.8658 & 1.054 & 6.5967 & 6.6550 & 1.0302 & 0.8948 & 0.9983 & 1.487 \\
\hline 0.80 & 6.1654 & 6.9730 & 0.8616 & 11.876 & & & & & & \\
\hline
\end{tabular}


pulation analysis for $\mathrm{CH}_{4}$ and for $\mathrm{NH}_{3}$ in Tables 2 and 3: as the exponent for the $p$ function becomes larger, leading to a more stable molecular energy, too much charge is transferred from $\mathrm{C}$ or $\mathrm{N}$ to the $\mathrm{H}$ atoms. Similar effects are observed in the cases of $\mathrm{HCN}$ and $\mathrm{CH}_{3} \mathrm{NH}_{2}$, given in Table 6 .

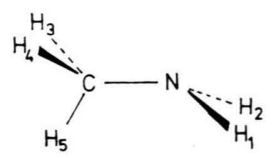

Fig. 8. Numbering of atoms in $\mathrm{CH}_{3} \mathrm{NH}_{2}$.

JOHANSEN ${ }^{21}$ has suggested that the bonding properties of molecules calculated using minimal GTO basis sets may be improved if more of the Gaussian functions are assigned to the description of the valence electrons and fewer to that of the core elec-

1 H. Preuss, Z. Naturforsch. 11 a, 823 [1956].

2 H. Preuss, Z. Naturforsch. 19 a, 1335 [1964].

3 H. Preuss, Z. Naturforsch. 20 a, 17, 21 [1965].

4 H. Preuss, Z. Naturforsch. 20 a, 1290 [1965].

5 A. IIARTMAnN, Z. Naturforsch. 26 a, 1228 [1971].

6 W. J. Hehre, R. F. Stewart, and J. A. Pople, J. Chem. Phys. 51, 2657 [1969].

7 W. J. Hehre and J. A. Pople, J. Amer. Chem. Soc. 92 , 2191 [1970].

8 R. Ditchfield, W. J. Hehre, and J. A. Pople, J. Chem. Phys. 52, 5001 [1970].

9 M. D. Newton, W. A. Lathan, W. J. Hehre, and J. A. Pople, J. Chem. Phys. 52, 4064 [1970].

10 W. J. Hehre, R. Ditchfield, and J. A. Pople, J. Chem. Phys. 53, 932 [1970].

11 E. Russeger, P. Lischia, and P. Schuster, Chem. Phys. Letters 12, 392 [1971]. trons. The use of this technique would undoubtedly improve the present results.

HEHRE and coworkers ${ }^{6}$ have found that, although least-energy minimized GTO's give a lower energy for molecules than do the GTO expansions of STO's, the latter usually require fewer functions in order to yield optimum values of charge distributions and dipole moments. They have also found that their STO-NG basis sets are usually applicable to a wider variety of molecules with less required re-scaling of parameters.

\section{Acknowledgments}

P. A. Clark wishes to thank Professor H. Preuss for the hospitality extended to her as a guest at the Institute für Theoretische Chemie, and Dr. W. MeYer for stimulating discussions. P. A. C. is indebted to Vassar College for a leave-of-absence during the academic year $1971-72$.

12 M. Jungen, Theoret. Chim. Acta 22, 225 [1971].

13 J. L. Whitten, J. Chem. Phys. 39, 349 [1963].

14 These functions were provided by the research group of this Institute.

15 This program was kindly provided by Drs. W. MEYER and P. Pulay of this Institute.

16 W. E. PAlke and W. N. Lipscomb, J. Amer. Chem. Soc. 88, 2384 [1966].

17 A. D. McClellan, Tables of Experimental Dipole Moments, W. H. Freeman \& Sons, San Francisco 1963.

18 A. D. McLean, J. Chem. Phys. 37, 627 [1962].

19 Numbering of atoms as shown in Figure 8.

20 L. Pedersen and K. Morokuma, J. Chem. Phys. 46, 3941 [1967].

21 H. Johansen, Theoret. Chim. Acta 21, 9 [1971]. 